\title{
An Ontology Based Approach for Regulatory Compliance of EU Reg. No 995/2010 in Greece ${ }^{\dagger}$
}

\author{
Efthymios Lallas *, Anthony Karageorgos and Georgios Ntalos
}

Citation: Lallas, E.; Karageorgos, A.; Ntalos, G. An Ontology Based Approach for Regulatory Compliance of EU Reg. No 995/2010 in Greece. Eng. Proc. 2021, 9, 38. https:// doi.org/10.3390/engproc2021009038 Academic Editors: Dimitrios Kateris and Maria Lampridi

Published: 31 December 2021

Publisher's Note: MDPI stays neutral with regard to jurisdictional claims in published maps and institutional affiliations.

Copyright: (C) 2021 by the authors. Licensee MDPI, Basel, Switzerland. This article is an open access article distributed under the terms and conditions of the Creative Commons Attribution (CC BY) license (https:// creativecommons.org/licenses/by/ $4.0 /)$.
Applied Informatics and Digital Technologies Laboratory, Department of Forestry, Wood Sciences and Design, School of Technology, University of Thessaly, 43100 Karditsa, Greece; karageorgos@uth.gr (A.K.); gntalos@uth.gr (G.N.)

* Correspondence: elallas@uth.gr

† Presented at the 13th EFITA International Conference, online, 25-26 May 2021.

\begin{abstract}
Illegal logging has always been considered as a major environmental and social global concern, as it is directly associated with deforestation and climate change. Nowadays, EU Regulation No 995/2010 has been successfully enforced to impede the placement of illegally produced timber within the EU market and therefore to efficiently enhance sustainable forest management and restore ecosystem balance. However, EU 995 regulatory compliance and enforcement itself is quite complex, since it requires long-term conformity, on a common basis for various heterogeneous groups and communities of stakeholders, in a global, even beyond EU, rule regulation framework. To make things worse, such a framework must be applied to the entire supply distribution chain and a wide variety of wood products, ranging from paper pulp to solid wood and flooring. Hence, in such complex and multivariate information environments, an ontological approach can more efficiently support regulatory compliance and knowledge management, due to its openness and richness of semantics for representing, analyzing, interpreting and managing such kind of information. In this paper, a rulebased regulatory compliance ontology is proposed, which fully captures EU Regulation No 995/2010 concepts and compliance rules and guidelines, as well as Greek legislations governing wood trade. The proposed ontology can be the basis for a computerized system providing automated support for illegal wood trade and monitoring EU regulation information provision and audit information storage and analysis.
\end{abstract}

Keywords: illegal wood trade; EU Regulation No 995/2010; regulatory compliance; ontology engineering

\section{Introduction}

Illegal logging has always been considered as a major environmental and social global concern, as it is directly associated with deforestation and climate change. Over the past few decades, there has been a worldwide attempt to monitor and eliminate illegal logging motivations and activities via appliance of appropriate regulation frameworks and by establishing monitoring organizations for assuring conformity behavior. The EU community has successfully enforced EU Regulation No 995/2010 (EUTR) [1] to its member states for efficiently dealing with this matter.

The main goal of EU Regulation No 995/2010 is to prohibit placing illegally harvested timber and products within the EU market. For this purpose, it requires that traders maintain valid formal records of who they buy from and who they sell to and that operators apply a due diligence system including risk assessment and risk mitigation procedures [2] Unfortunately, supply chain traceability is a challenging task for monitoring organizations, as there is commonly not sufficient evidence of wood product originality and of the intermediate merchant transactions. Furthermore, supply chain complexity is an additional issue, since it impedes the long-term conformity of heterogeneous groups and communities 
involved, such as stakeholders and suppliers. Several research works have focused on solutions targeting supply chain traceability and complexity [3-9].

In such complex regulation environments comprising multivariate information, an ontology-based data model could better support compliance and knowledge management due to its openness and richness of semantics.

The work described in this paper focuses on a regulatory compliance ontology model, aiming to facilitate meeting EU Regulation No 995/2010 compliance guidelines and therefore to efficiently tackle the tremendous consequences of illegal logging. A case study in Greece was considered. The proposed ontology can be the basis for the implementation of a computerized regulation compliance system, providing automated support for illegal wood trade monitoring and audit information storage and analysis.

\section{Description of the Regulatory Compliance Ontology of EU Regulation No 995/2010 in Greece}

In this section the main ontology entities are identified based on the EU Regulation No 995/2010 guidelines, applied to a case study in Greece. The main building blocks of constructing such an ontology are ontological subdomains and class objects with common characteristics, which represent application-domain concepts. Class individuals are used for accurate ontology description, which are the instances of a class object.

More specifically, the proposed ontology comprises six regulatory compliance domains, which are deemed as necessary for fully representing the EUTR regulation domain in Greece. Each domain is associated with a number of class entities. The proposed domains are as follows: (i) the administration authority domain including classes corresponding to the respective authorities of Greece and the EU. The central competent authority in Greece is the Department of Planning and Forest Policy of the General Secretariat of Development and Protection of Forests and Agri-Environment of the Ministry of Environment and Energy, with the support of Distribution and Trade Department of Forest Products and Species (Convention on International Trade in Endangered Species (CITES) of Wild Fauna and Flora). There are also regional competent delegated authorities for each region of Greece, such as the Forest Secretariat of the Greece Regional Administrations or the Secretariat of Forest Coordination and Inspection. Regional competent authorities usually cooperate with regional audit services, for carrying out compliance audit checks, and inter-ministerial technical expertise working groups, for technical assistance, whenever required; (ii) the supply chain domain, including trader and operator classes, along with their attributes, and additional general classes, such as merchants, retailers, manufacturers, suppliers, commercial customers, end (final) consumers, agents, buyers, and sellers; (iii) the directory/registry domain, including all relevant national and regional directories of traders, operators, and monitoring organizations; (iv) the product domain including class individuals related to wood products, such as code, name, description, batch order, origin country, quantity, value, invoice, packing list, delivery note, life cycle, and product list within, and out of the scope of EUTR; (v) the audit control domain, including class individuals related to audit control status (premises, field audit control, and due-diligence service audit) and associated attributes, such as risk assessment, risk mitigation, risk status, risk assessment report, and penalty/fines; (vi) the documentation domain comprising documentation record repository and maintain record period classes, and two subdomains-(a) certificate and license validation subdomain, including classes related to validation documentation (forest law enforcement, governance, and trade-FLEGT license, voluntary partnership agreements (VPAs) CITES certificate, 3rd-party-verified scheme, forest stewardship council (FSC), programs for the endorsement of forest certification(PEFC), and chain of custody $(\mathrm{CoC})$ certification) [10] and (b) supply chain documentation subdomain, including classes related to product documentation, with some of them also included in the product domain. 


\section{Regulatory Compliance Ontology Design of EU Regulation No 995/2010 in Greece}

The next ontology design step involves the identification of rule compliance constraints based on EUTR articles and related law frameworks [11-14], as well as regulation rules that govern traders and operators, competent authorities, and monitoring organizations. Such constraint requirements completely define the roles and the relationships among ontology class individuals, and they are reflected on the overall regulatory compliance ontology layout. Specifically, each EU country, including Greece, has its own delegated central and regional competent authorities responsible for the correct application of EUTR regulations on all parties involved. This is achieved by the consulting support of monitoring organizations for properly executing these relevant control checks. Monitoring organizations are EU-based industry or trade associations, certification bodies, or other service providers, which offer consulting services to assist wood enterprises in achieving compliance with due diligence requirements. In general, regulation compliance audit checks require, for both traders and operators, the certified record maintenance of particular transaction information for a certain period, in order to enable supply chain traceability. Moreover, operators should be able to apply a due-diligence service audit check, with the guidance of monitoring organizations, in order to assess the risk of illegal timber in the supply chain, and to provide additional information and verification documentation in case there is a risk assessment that needs to be mitigated.

Due to the large number of classes and their associated relationships included in the EUTR compliance ontology, it is hard to show and clearly discriminate all of them in a single layout. It would be more practical to represent a subset of interdomain class relationships as a sample for the proposed regulatory compliance ontology. For this reason, we have chosen the interdomain class entity relationships of a typical due-diligence audit check. A due-diligence audit check is a three-step procedure: The first step requires access to relevant information maintained in the compliance documentation repository. This step is mandatory for both traders and operators, while the next two steps are mandatory only for operators. The second step, termed risk assessment, aims for determining and classifying risk status. There could be either "no risk" status, in case a FLEGT or CITES license is provided, "negligible" (low/medium) risk, or "non-negligible" (high) risk status. Risk mitigation measures need to be performed for the latter two risk status cases, which necessitates the initiation of the third step. Its basic goal is to mitigate all risk status cases, down to "negligible" risk status and finalize successfully the audit control procedure. In any case, a risk assessment report is required, in addition, so as to officially finalize the procedure, by writing down its results in detail. The regulatory compliance ontology layout for highlighting class relationship representation of a typical due-diligence audit check is depicted in Figure 1.The relations between class individuals based on their specified roles according to EUTR framework clauses are indicated by arrows.

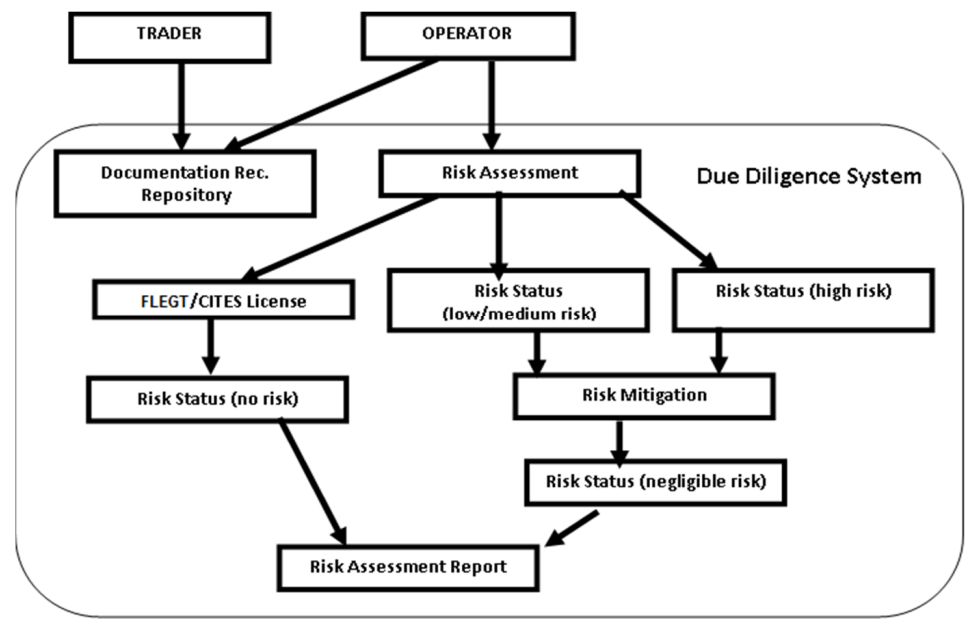

Figure 1. Regulatory compliance ontology layout of a due-diligence audit check. 


\section{Discussion and Conclusions}

For over a decade, the EU community has successfully enforced EU Regulation No 995/2010 for tackling illegal harvesting and its tremendous consequences in forest management, ecosystem balance, and climate change. However, supply chain traceability and related data complexity are quite challenging issues that require efficient support for fast audit checks and effective risk assessment and risk mitigation procedures. In addition, each EU member must convert the EUTR into national law standards with the least exceptions and law deviations from the basic EU law framework.

This paper proposes a regulatory compliance ontology to support EU Regulation No $995 / 2010$ compliance and knowledge management. The proposed ontology is a complete representation of EUTR focusing on its prohibition requirements, the competent authorities, and the required audit controls, while paying particular emphasis to compliance requirements in the context of Greek legislations. Furthermore, the proposed ontology describes in full detail the concepts in the domain of illegal wood trade, as well as the relationships that hold between these concepts. Its analytical representation is appropriate for the support of decision making in EUTR critical risk assessment issues. Finally, the ontology implementation is independent of any software platform and could thus be the basis for developing computerized audit monitoring information systems.

Funding: This research received no external funding.

Institutional Review Board Statement: Not applicable.

Informed Consent Statement: Not applicable.

Conflicts of Interest: The authors declare no conflict of interest.

\section{References}

1. Available online: https:/ / eur-lex.europa.eu/LexUriServ/LexUriServ.do?uri=OJ:L:2010:295:0023:0034:EN:PDF (accessed on 11 November 2021).

2. Available online: https:/ / ec.europa.eu/environment/forests/timber_regulation.htm (accessed on 11 November 2021).

3. Holopainen, J.; Toppinen, A.; Perttula, S. Impact of European Union Timber Regulation on Forest Certification Strategies in the Finnish Wood Industry Value Chain. Forests 2015, 6, 2879-2896. [CrossRef]

4. Leipold, S. How to move companies to source responsibly? German implementation of the European Timber Regulation between persuasion and coercion. For. Policy Econ. 2016, 82, 41-51. [CrossRef]

5. Koch, G.; Haag, V. Control of Internationally Traded Timber-The Role of Macroscopic and Microscopic Wood Identification against Illegal Logging. J. Forensic Res. 2015, 6, 1000317. [CrossRef]

6. McDermott, C.L.; Sotirov, M. Apolitical economy of the European Union's timber regulation: Which member states would, should or could support and implement EU rules on the import of illegal wood? For. Policy Econ. 2018, 90, 180-190. [CrossRef]

7. Köthke, M. Implementation of the European Timber Regulation by German importing operators: An empirical investigation. For. Policy Econ. 2020, 111, 102028. [CrossRef]

8. Dudik, R.; Sisak, L. Placing Timber and Timber Products on the Market in the Czech Republic and Related Economic Impacts. In Proceedings of the IUFRO Symposium 2014, Sopron, Hungary, 26-28 November 2014; pp. 35-42.

9. Neshataeva, E.; Karjalainen, T. Impact of the EU Timber Regulation on Russian companies exporting wood and wood-based products. Resour. Technol. 2015, 12, 37-44. [CrossRef]

10. Available online: https:/ / www.flegtlicence.org/flegt-certification-cites (accessed on 11 November 2021).

11. Available online: https:/ / eur-lex.europa.eu/legal-content/EN/TXT/?uri=CELEX\%3A32012R0607 (accessed on 11 November 2021).

12. Available online: https://eur-lex.europa.eu/legal-content/EN/TXT/?uri=CELEX\%3A32012R0363 (accessed on 11 November 2021).

13. Available online: https://www.e-nomothesia.gr/kat-dasos-thera/kya-134627-5835-2015.html (accessed on 11 November 2021).

14. Available online: https://dasarxeio.com/wp-content/uploads/2015/12/134382_5229_2015.pdf (accessed on 11 November 2021). 